\title{
Relações Entre Conteúdo e Expressão na Fala do Jornal Nacional: uma Abordagem Semiofonoestilística
}

\author{
Conrado Moreira Mendes* \\ Ana Cristina Fricke Matte ${ }^{* *}$
}

\begin{abstract}
Resumo: Este artigo é fruto de pesquisa (MENDES, 2009) cujos principais objetivos foram: (1) analisar como se constroem os sentidos dos textos do principal telejornal brasileiro: o Jornal Nacional (JN) e (2) verificar de que maneira o conteúdo e a expressão da fala do JN poderiam estar ou não relacionados. Ao se trabalhar com os dois planos da função semiótica, no que concerne à realização da língua, requisitou-se, de um lado, a fonética acústica, disciplina que analisa as características físicas dos sons da fala humana e, de outro lado, ancorou-se no escopo teórico-metodológico da semiótica de linha francesa, disciplina que se interessa principalmente pelos mecanismos intratextuais de produção de sentido do texto. Quanto ao primeiro objetivo, ao se fazer uma análise semiótica das matérias do Jornal Nacional, puderam ser depreendidas algumas estruturas invariantes sobre as quais se constrói o discurso desse noticiário. As matérias foram analisadas principalmente no que tange ao nível discursivo, previsto pelo percurso gerativo de sentido. Quanto ao segundo objetivo, partindo da proposta de Matte (2008), cruzaram-se dados fonéticos com dados semióticos provenientes do nível discursivo. Resultados inéditos apresentados pela pesquisa apontam para um quadro em que alguns elementos do plano do conteúdo afetam, na fala do Jornal Nacional, elementos do plano da expressão em análises estatisticamente significantes.
\end{abstract}

Palavras-Chave: semiótica do discurso; conteúdo; fonética acústica; expressão; telejornalismo; Jornal Nacional; semiofonoestilística.

\section{Introdução}

O presente artigo aporta alguns resultados de nossa pesquisa de mestrado (MENDES, 2009) desenvolvida no âmbito da semiofonoestilística. Tal neologismo,

\footnotetext{
* Universidade de São Paulo, Faculdade de Filosofia Letras e Ciências Humanas. Programa de Pós-Graduação em Semiótica e Lingüística Geral. Bolsista de Doutorado da Fundação de Amparo à Pesquisa do Estado de São Paulo - FAPESP. Av. Prof. Luciano Gualberto, 40, Cidade Universitária. 05508-900 - São Paulo, SP Brasil. conradomendes@yahoo.com.br

** Universidade Federal de Minas Gerais. Faculdade de Letras. Programa de Pós-Graduação em Estudos Lingüísticos. Av. Antonio Carlos, 6627, Faculdade de Letras, sala 3097. Pampulha. 31270-901 - Belo Horizonte, MG - Brasil. anacrisfm@ufmg.br
} 
proveniente do nome do grupo de pesquisa Semiofon: Semiose e Fonoestilística ${ }^{l}$, referese a um recente campo de estudo que tem por objetivo analisar conteúdo e expressão da fala, por meio de pesquisa de natureza interdisciplinar que relaciona a semiótica de linha francesa e a acústica e tecnologia da fala. A semiofonoestilística, assim, ancora-se na principal dicotomia saussure-hjelmsleviana, segundo a qual a realização da língua pressupõe um conteúdo e uma expressão, ponto de partida para analisar esses dois lados da mesma folha de papel, numa alusão direta à metáfora de Saussure (2006, p. 131).

Nossa investigação debruçou-se sobre o estudo da fala do Jornal Nacional, principal telejornal da TV brasileira. Desse modo, na esteira da semiofonoestilística, contamos com dois pressupostos teóricos diferentes: de um lado a semiótica de linha francesa, teoria do texto e do discurso, que estuda a significação, cujo maior expoente é A. J. Greimas. De outro, a fonética acústica, que estuda ondas sonoras mecanicamente produzidas e que, por isso, trabalha com dados numéricos, estatísticos.

Os objetivos da pesquisa foram analisar como se constroem os sentidos dos textos do Jornal Nacional (JN), e verificar de que maneira o conteúdo e a expressão da fala desse telejornal poderiam estar ou não relacionados. Este artigo, assim, divide-se em duas partes. Na primeira, analisamos semioticamente como se dá a construção dos sentidos dos textos das matérias do JN. As matérias são examinadas principalmente quanto ao nível discursivo previsto pelo percurso gerativo de sentido, especificamente a semântica discursiva, pela análise de temas e figuras. Além disso, também desse nível, analisamos a aspectualização, principalmente em relação ao tempo, ou seja, o andamento do conteúdo do texto, o que confere às análises uma perspectiva, por vezes, tensiva. Procuramos estabelecer padrões, estruturas invariantes sobre as quais se constrói o discurso jornalístico.

Na segunda parte, relacionamos dados fonéticos e dados semióticos, objetivando compreender como se dá o engendramento do sentido por meio da relação entre conteúdo e expressão. $\mathrm{O}$ intuito foi perceber se há relação direta entre expressão e conteúdo e de que maneira um poderia ser afetado pelo outro. Com isso, para além de uma análise semiótica do discurso, o objetivo da pesquisa foi conjugar também uma análise fonética da fala. Se, para a teoria semiótica, o discurso se concretiza pelo texto, acreditamos que a representação da expressão da fala pode oferecer pistas para se compreender a natureza do texto, levando em consideração seus dois funtivos: expressão e conteúdo, e a relação entre eles. Antes da apresentação das análises semióticas, discorreremos sobre a metodologia utilizada para a obtenção dos dados fonéticos da pesquisa.

\footnotetext{
${ }^{I}$ O grupo de pesquisa desenvolvido e coordenado pela Prof ${ }^{a}$. Dr ${ }^{\mathrm{a}}$. Ana Cristina Fricke Matte tem como principal objetivo é a síntese de fala emotiva do português brasileiro. Os projetos do Semiofon dedicam-se à pesquisa básica sobre fala emotiva (fonética e semiótica), produção de software relacionados à análise e síntese de fala, bem como relacionados à coleta de dados de fala, e também ao ensino.
} 


\section{Metodologia}

Analisamos uma semana aleatória do Jornal Nacional, que é exibido de segunda a sábado. Foi condição imprescindível que em tal semana os apresentadores oficiais, William Bonner e Fátima Bernardes, estivessem presentes de segunda a sexta; no sábado, eles são substituídos por outros dois apresentadores. Isso se deve ao fato de que este estudo tem como objeto a fala do Jornal Nacional e, por isso, optamos por uma semana típica do JN. A semana analisada é compreendida pelos dias 5 a 10 de maio de 2008. Cada edição do JN possui diariamente cerca de 13, 14 matérias. Dessa gama extraímos três matérias por dia, totalizando 17 e não 18 matérias, que compõem o corpus desta pesquisa, pois ela prescindiu de uma matéria da quarta-feira, pelo fato de não se enquadrar tematicamente no critério que se convencionou chamar de matérias nacionais, internacionais e locais. A escolha desse critério se pautou principalmente pelo lugar onde se desenrolam os acontecimentos, o que, de certa forma, acaba por definir a editoria em que entram tais matérias. A razão de analisarmos três matérias por dia (com exceção de quarta-feira, em que foram analisadas duas) e não as 13 ou 14, quer dizer, toda a edição desse noticiário, decorre do fato de que a análise acústica, ainda que seja feita por um programa de computador, é um processo lento e praticamente manual. O corpus da pesquisa foi composto de 6455 segmentos de VV (de vogal a vogal). Para a análise acústica, utilizou-se tão somente o som das matérias, descartando-se a parte visual. Esse som foi retirado do site do noticiário (http://jornalnacional.globo.com/), no qual as matérias são dispostas individualmente. Procedemos então à extração do vídeo completo, ou seja, com o áudio, por meio de um programa compatível ao navegador Mozilla, chamado Download Helper. Esse programa salva os vídeos em formato de vídeo $f l v$, os quais, em seguida, foram convertidos para o formato de áudio .wav pelo programa conversor chamado Total Video Converter. Em relação ao texto de cada matéria, o próprio site do noticiário os disponibiliza, de modo que não foi necessária a transcrição de cada matéria para as análises semióticas. O corpus foi analisado pelo software livre para análise acústica Praat (www.fon.hum.uva.nl/praat/) e conjuntamente foi utilizado o script Beat Extractor traduzido por Barbosa (2006), que segmenta automaticamente segmentos VV.

Após as segmentações, foram feitas transcrições fonológicas, com base na tabela proposta por Albano \& Moreira (1996). Optamos pela transcrição fonológica, pois a análise pressupõe que a realização acústica dos sons de cada língua não é fixa, embora exista uma intenção fonológica para cada execução que permite a identificação de sons diferentes mesmo quando sua realização sobrepõe parâmetros acústicos. Os resultados encontrados no Praat foram, por sua vez, analisados pelo software livre de análise estatística, chamado $R$ (www.r-project.org/). A seguir, para fim de exemplificação, apresentamos uma imagem da segmentação de uma sentença do corpus da pesquisa. No caso, observamos a sentença sem a ajuda de pedreiros. Na parte de cima está a representação da curva de onda e, abaixo dela, o espectrograma, onde estão os formantes. Na terceira parte, encontra-se a segmentação dos segmentos VV pelas barras azuis e, entre tais barras, a transcrição fonológica de cada segmento: 


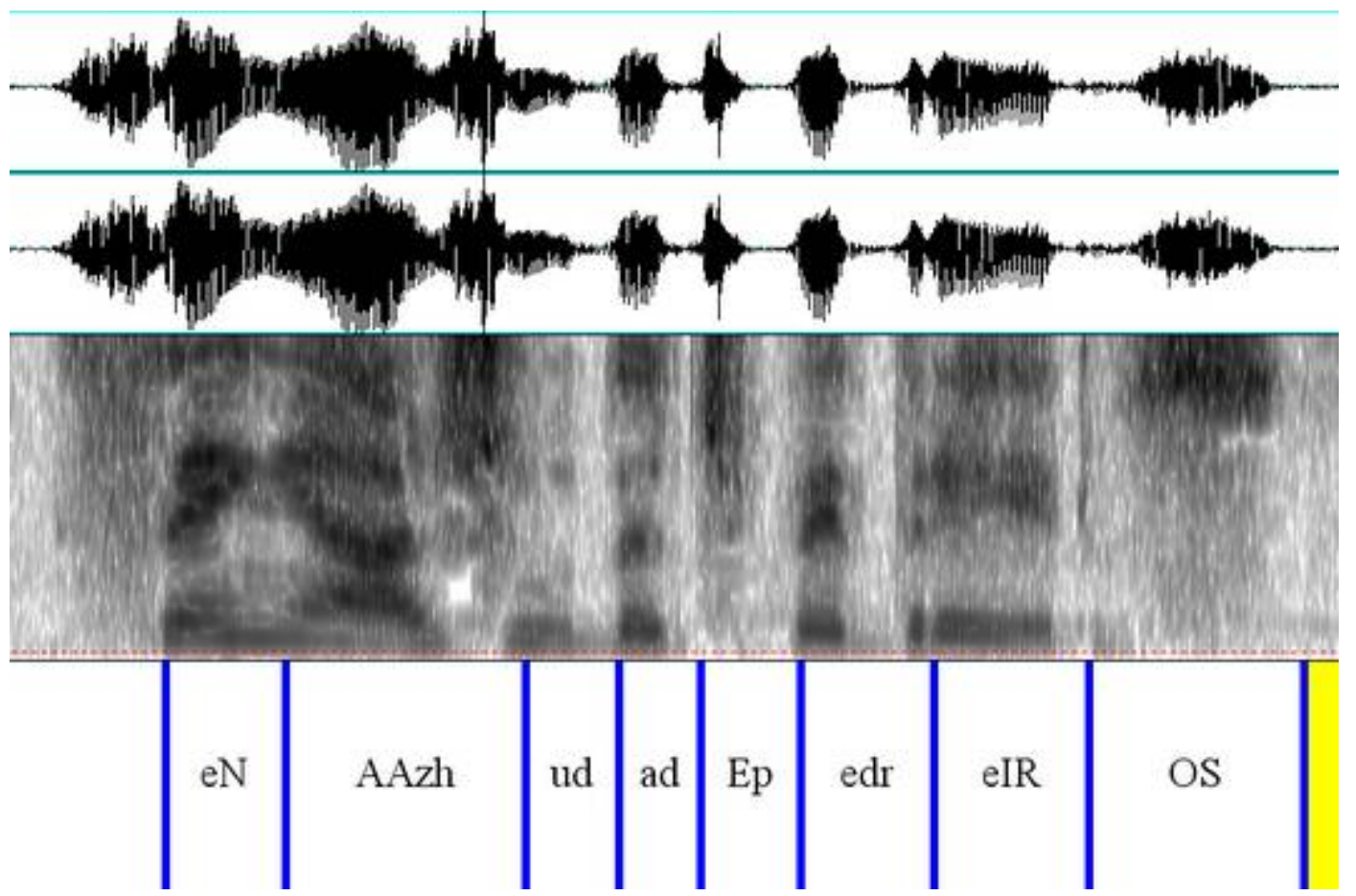

\section{O conteúdo da fala do JN}

Nesta seção, são realizadas as análises semióticas do plano do conteúdo dos textos das matérias do Jornal Nacional. Isso quer dizer que se pretende verificar o que é dito e como se faz para dizer o dito, ou seja, os efeitos de sentido construídos no e pelo texto. Como foi apontado na introdução deste artigo, o nível do percurso gerativo privilegiado para a análise é o discursivo. Para efeito de demonstração, serão apresentadas duas das 17 análises realizadas pela pesquisa. A íntegra dos dois textos aqui analisados se encontra no anexo do artigo.

\subsection{Análise 1}

A matéria da categoria nacional do dia 5 de maio trata do caso da investigação de um deputado envolvido num esquema de desvio de dinheiro. A primeira análise a ser feita é a dos temas, figuras e isotopias encontrados no texto. Para isso, faremos uma pequena revisão da teoria, o que será feito sempre que for pertinente.

O nível discursivo, previsto pelo percurso gerativo de sentido, articula-se numa sintaxe e numa semântica discursivas. À primeira cabem as projeções da pessoa, do tempo e do espaço no enunciado. A semântica discursiva, por sua vez, tem por objeto as 
tematizações e as figurativizações. Segundo Greimas e Courtés (2008, p. 435), "o percurso narrativo pode ser convertido, no momento da discursivização, quer em um percurso temático, quer, numa etapa ulterior, num percurso figurativo". Isso quer dizer que as relações de conjunção/disjunção do nível narrativo concretizam-se, ao passar para o discursivo, recobrindo-se sob a forma de temas e, mais concretamente, sob a forma de figuras. Para Fiorin (2006, p. 91), abstração e concretude não são termos que se opõem de maneira privativa, mas que repousam em um continuum que vai do mais abstrato ao mais concreto. Os textos figurativos constroem um simulacro da realidade, ao passo que, os textos temáticos tentam explicar essa realidade, estabelecendo para isso relações. Salienta-se que, quando se fala em textos figurativos ou temáticos, não se trata de categorizar cada texto como estritamente temático ou estritamente figurativo; significa dizer que esses textos são predominantemente figurativos ou predominantemente temáticos. Em relação às figuras, Barros (2002, p. 124) afirma ser esse o lugar da ideologia nos discursos, já que as figuras de um texto não estão ali por acaso, mas são, antes de mais nada, o resultado da escolha do enunciador. Temas e figuras se disseminam no texto criando percursos temáticos e figurativos. A recorrência desses percursos ou, em outras palavras de categorias sêmicas, é chamada por Greimas e Courtés $(2008$, p. 276$)$ de isotopias. Tal termo advém do domínio da física, sendo aquilo que dá ao texto uma coerência semântica ou um plano de leitura.

Após essa pequena incursão teórica, vejamos agora o trecho inicial da matéria nacional do dia 5 de maio:

A Justiça de São Paulo mandou para o Supremo Tribunal Federal o processo em que o nome do deputado federal Paulo Pereira da Silva, do PDT, aparece citado como beneficiário de um esquema de desvio de dinheiro do Banco Nacional de Desenvolvimento Econômico e Social.

Observamos no trecho acima uma recorrência de figuras, pois se encontram ali elementos que recriam por simulacro o mundo natural: Justiça de São Paulo; Supremo Tribunal Federal; processo; deputado federal; Paulo Pereira da Silva; beneficiário; desvio de dinheiro; Banco Nacional de Desenvolvimento Econômico e Social. O tema da corrupção e o tema da investigação são recobertos por tais figuras, formando, pois, dois percursos temático-figurativos. O principal tema do primeiro percurso é o da corrupção. O outro percurso, o da investigação, fica mais evidente no próximo excerto:

Para o Ministério Público, há indícios da participação do deputado no esquema. Em entrevista, a procuradora que cuida do caso disse que os indícios vão além das escutas telefônicas. "O indício que seja ele são as ramificações das investigações e, na verdade, algumas vezes não foi só citado o nome Paulinho".

Para uma melhor visualização de ambos os percursos temáticos, propomos a seguinte disposição: 


\section{Percurso temático da corrupção:}

Temas: citação do nome do deputado em processo que o cita como beneficiário no esquema de corrupção $\rightarrow$ ausência do político na Câmara dos Deputados $\rightarrow$ Declaração de defesa do deputado pela Força Sindical

\section{Percurso temático da investigação}

Temas: indícios da participação do deputado no esquema $\rightarrow$ evidências da participação de 11 prefeituras $\rightarrow$ indícios do envolvimento de funcionários do BNDES $\rightarrow 11$ pedidos de prisão $\rightarrow$ envio de cópias do processo ao Tribunal Regional Federal e ao Supremo Tribunal Federal $\rightarrow$ abertura de processo contra do deputado condicionada ao parecer da Procuradoria Geral da República.

Vemos que o percurso temático da corrupção dá origem ao segundo percurso, o da investigação. Ambos estão intimamente relacionados em todo o texto, uma vez que o segundo depende do primeiro, quer dizer, não havendo suspeitas de corrupção, não caberiam investigações, ainda que no trecho "Foram feitos 11 pedidos de prisão" exista uma sanção pragmática, que é justamente o final do percurso temático da investigação. Houve um contrato que foi quebrado (pela corrupção) e a incriminação é a sanção cognitiva, enquanto o pedido de prisão, a sanção pragmática.

O tema da corrupção é figurativizado principalmente por "desvio de dinheiro" e o tema da investigação é concretizado pela figura "escutas telefônicas". Em relação à isotopia do texto, é válido dizer que se trata de uma isotopia da corrupção, uma vez que a recorrência de tais categorias sêmicas cria um plano de leitura, um todo de sentido, que remete à corrupção. Essa isotopia da investigação/justiça estaria circunscrita a uma isotopia maior, a da corrupção, uma vez que a segunda isotopia só existe em função da primeira. Como aponta Barros (2002, p. 126), relações entre isotopias podem ser metafóricas ou metonímicas. Naquela existe uma ligação por similaridade e nesta por contiguidade do conteúdo. A relação, portanto, entre a isotopia da investigação/justiça e da corrupção se enquadra no segundo tipo descrito pela autora, já que se trata de uma relação todo-parte. Por fim, a figura desvio de dinheiro é axiologizada disforicamente, ao passo que a figura escutas telefônicas possui um valor positivo naquele microuniverso semântico, pois ela reveste o tema da investigação. Outras duas figuras recorrentes no texto que concretizam o tema da investigação são indícios e evidências, elementos que fazem parte do jargão policial e que remetem a elementos concretos. Assim como em "escutas telefônicas", elas teriam um valor eufórico, ao passo que a figura do "desvio de dinheiro", um valor disfórico.

Outro conceito-chave para a presente análise é o de aspectualização, "a disposição, no momento da discursivização, de um dispositivo de categorias aspectuais mediante as quais se revela a presença implícita de um actante observador" (GREIMAS; COURTÉS, 2008, p. 39). Em outras palavras, a aspectualização é o ponto de vista desse observador, que dá um aspecto ao espaço, tempo e pessoa. Para Fiorin (1999), o conceito de foria, ao ser conjugado a uma intensidade e a uma extensidade e ao projetar- 
se no tempo e no espaço, produz efeitos de andamento e ritmo discursivos. Em resumo, o actante observador sobredetermina as categorias da enunciação, relacionando-as a uma continuidade ou a uma descontinuidade. Em relação ao tempo, a aspectualização consiste principalmente no andamento do texto, tornando-o mais rápido ou mais lento. Andamento mais rápido, maior intensidade; andamento mais lento, maior extensidade.

Os percursos temático-figurativos descritos acima parecem se relacionar a um texto de andamento rápido. No texto em análise, há uma sucessão de fatos que coincide quase inteiramente com tais percursos. O texto, dessa forma, tem inicialmente um andamento rápido, pois há uma sucessão ininterrupta de fatos que se sucedem. Vejamos, portanto, como ocorre a sucessão desses fatos:

1) Abertura de processo contra deputado supostamente envolvido com desvio de dinheiro do BNDES;

2) Ausência do deputado em seu gabinete para preparar explicações ao seu partido;

3) Existência de indícios contra o deputado, não apenas escutas telefônicas;

4) Suposta participação de 11 prefeituras;

5) Existência de do envolvimento de funcionários do BNDES;

6) Realização de 11 pedidos de prisão.

Após o sexto fato, surge uma explicação: "Prefeitos e deputados têm foro privilegiado. Por isso, o Ministério Público pediu e a Justiça Federal de São Paulo enviou cópias do processo ao Tribunal Regional Federal e ao Supremo Tribunal Federal". Essa passagem causa uma desaceleração no andamento do texto, uma vez que não se trata de um fato novo, mas de um esclarecimento dos trâmites legais envolvendo aqueles políticos. Em seguida, mais uma elucidação dessa natureza: "para processar $o$ deputado Paulo Pereira da Silva, o STF depende do parecer da Procuradoria Geral da República". Notamos haver uma manutenção da desaceleração do texto. A fala do procurador-geral Antônio Fernandes de Souza tampouco promove uma aceleração, pois não traz nenhum elemento novo: "A hora que chegar eu vou examinar para verificar. Se tiver alguma coisa, eu tomo as providências que eu sempre tenho tomado". O andamento volta a ficar mais rápido no final com uma declaração de defesa da Força Sindical: "Em nota, a Força Sindical defendeu seu presidente, dizendo que ele é vítima de implacável perseguição política". Tal declaração, no entanto, não tem a força de um novo acontecimento e, por isso, pouca aceleração do andamento consegue promover. Em termos tensivos, é possível dizer que o texto começa com uma intensidade alta, mas, quando se aproxima do meio para o final, essa intensidade começa a diminuir, pois o andamento, antes rápido, torna-se mais lento.

A matéria da categoria nacional do dia 5 de maio mostra um texto predominantemente figurativo. Esse predomínio de figuras encadeadas faz com que o texto tenha inicialmente um andamento rápido, que só perde a força aproximadamente a partir do meio do texto. Não pretendendo generalizar, o texto jornalístico obedece a uma forma padrão chamada de pirâmide invertida, a partir da qual as informações principais, 
(o lide, do inglês lead) tais como "o que", "como", "quando", "onde" e "por que" vêm o quanto antes. No final, alguns esclarecimentos ou explicações. Dessa forma, a matéria nacional do dia 5 de maio tem uma intensidade decrescente e um texto que procura recriar, por meio de figuras, o mundo natural.

\subsection{Análise 2}

A segunda matéria analisada pertence à categoria local do dia 5 de maio e trata das consequências deixadas pelo ciclone extratropical que atingira o Sul do Brasil no fim de semana anterior. Observemos os dois primeiros parágrafos:

A Defesa Civil em Porto Alegre confirmou hoje a segunda morte causada pelo ciclone extratropical que atingiu a Região Sul do Brasil no fim de semana.

Depois da chuva, a preocupação agora é com os rios que não param de subir. Em Taquara, a 70 quilômetros de Porto Alegre, o Rio dos Sinos está oito metros acima do nível normal. Centenas de casas ficaram submersas.

No primeiro parágrafo, encontram-se figuras que recobrem o tema da morte e, no segundo, figuras que recobrem o tema da destruição. O tema da destruição, no entanto, é mais recorrente, formando um percurso temático-figurativo da destruição. Mais adiante, outro tema é observado pela frase "De barco, os moradores ainda tentam salvar alguns móveis". Nota-se aqui um pequeno percurso temático-figurativo da sobrevivência, que não chega a compor um percurso independente, mas, sim, faz parte do próprio percurso da morte. A sobrevivência estaria, nesse caso, na posição de negação da morte. Mais adiante, encontra-se um percurso figurativo da destruição: "chuva", "vento de mais de $100 \mathrm{~km} / \mathrm{h}$ ", "árvores arrancadas", "casas destruidas", "redes elétricas destruidas", "casas sem luz", "a calçada" e "um veículo que estacionava". Em seguida, mais elementos do mundo natural compõem tal percurso com as figuras: "3 mil pessoas desabrigadas", "duas vítimas" e "um homem afogado". $\mathrm{Na}$ segunda parte da matéria, que trata dos estragos causados em Santa Catarina, a destruição é figurativizada por "rodovia interditada", "pista inundada", "rio que transbordou", "engarrafamento de 14 km", "casa arrastada", "enchente", "pertences espalhados pelo terreno", "ruas transformadas em rios" e "1600 pessoas desalojadas". Pelo que se pode observar no texto, o percurso figurativo sempre recobre o percurso temático. A isotopia do texto é a da catástrofe, talvez um termo mais abrangente que destruição. Elementos recorrentes no texto levam à formação de um efeito de sentido final, que é justamente esse efeito ligado à calamidade pública. Tal percurso temáticofigurativo é valorado negativamente pelo texto, ou seja, cria um efeito disfórico.

Quanto à aspectualização, o texto apresenta um andamento acelerado no início, como vemos no trecho seguinte:

A Defesa Civil em Porto Alegre confirmou hoje a segunda morte causada pelo ciclone extratropical que atingiu a Região Sul do Brasil no fim de semana. Depois da chuva, a preocupação agora é com os rios que não param de subir. 
Em seguida, o texto sofre uma desaceleração, já que descreve as consequências da passagem do ciclone:

Em Taquara, a 70 quilômetros de Porto Alegre, o Rio dos Sinos está oito metros acima do nível normal. Centenas de casas ficaram submersas.

Mais adiante, o texto volta a ter um andamento mais rápido, apresentando fatos novos:

No fim de semana, a chuva e os ventos de mais de $100 \mathrm{~km} / \mathrm{h}$ arrancaram árvores, destruíram casas e a rede elétrica de muitas cidades. Nove mil e quinhentos consumidores ainda estão sem luz. Em protesto, moradores de Guaíba, na Grande Porto Alegre, fecharam hoje uma das principais avenidas da cidade.

O texto perde novamente em aceleração, quando em seguida é apresentado um relato de uma mulher indignada com a falta de luz:

"Nós resolvemos protestar porque desde sexta-feira, às oito e meia, nós estamos sem luz. Estragou toda a nossa alimentação".

Dessa forma, o texto é construído de um andamento mais rápido seguido de um andamento lento. Diferentemente do anterior, o andamento desse texto se alterna em acelerado/desacelerado.

\subsection{Considerações sobre o andamento nos textos analisados}

As análises realizadas objetivaram perceber a existência de padrões recorrentes nas matérias jornalísticas do JN a partir de estruturas intradiscursivas subjacentes aos 17 
textos analisados na pesquisa. Alguns padrões foram observados. Em relação ao andamento, os textos analisados se estruturam de duas maneiras: (1) A primeira delas é um andamento acelerado inicial que decresce no decorrer do texto. Isso se deve à apresentação do fato principal da notícia, em termos semióticos, em decorrência de uma ruptura, de uma tensão. Em seguida, o texto perde em aceleração, devido a descrições, elucidações e contextualizações, o que semioticamente significa uma distensão, um maior relaxamento. Uma variação desse tipo de estrutura é um andamento não desacelerado no final, mas que não chega a ser acelerado. (2) A segunda forma de estruturação textual em termos de andamento é uma oscilação entre aceleração e desaceleração. Isso se deve, como vimos, à apresentação de um fato (ruptura/intensidade) para depois discorrer-se sobre esse fato (continuidade/extensidade), e assim sucessivamente. Esse padrão foi o segundo mais observado pelas análises. Desse modo, podemos afirmar que uma matéria longa, por trazer mais temas e figuras, tende a ter essa organização, ao passo que uma matéria mais curta possui uma organização parecida com a de número um. Os gráficos a seguir representam os dois tipos de organização quanto à aspectualização:
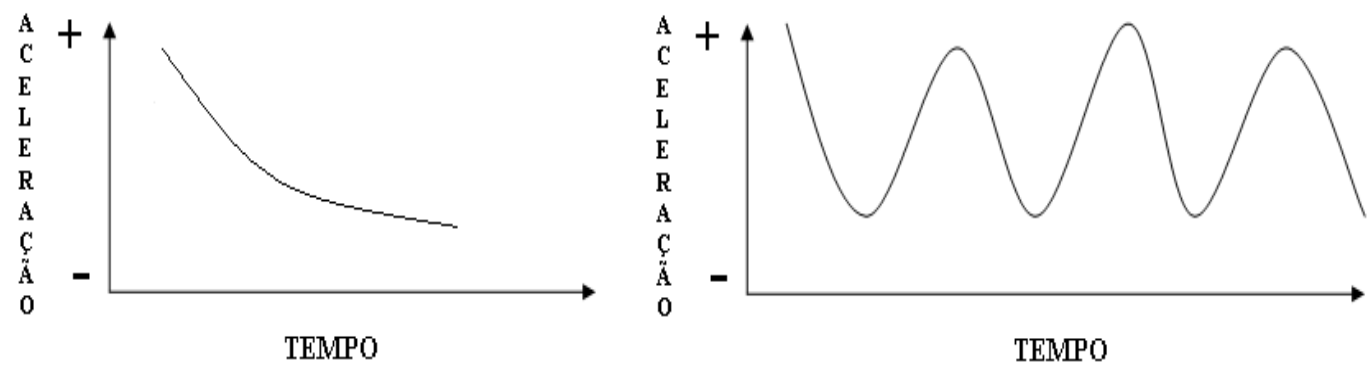

\subsection{Considerações sobre temas e figuras nos textos analisados}

Com relação às análises dos temas e figuras, podemos dizer que o discurso do Jornal Nacional é mais figurativo que temático, isto é, ao passar para o nível discursivo, categorias do nível narrativo são necessariamente tematizadas e frequentemente figurativizadas, criando um simulacro do mundo natural. Além disso, sendo um produto audiovisual, o Jornal Nacional faz uso de imagens para, de certa forma, reforçar essa figurativização presente no texto verbal, por meio de um processo de iconização.

Tentamos, ademais, perceber quais traços sêmicos subjazem aos temas encontrados nas matérias analisados. Cabe dizer que os temas podem, num nível mais abstrato, ser reduzidos a uma tensão entre um querer versus um dever. Na primeira matéria analisada, o político deve ser honesto; no entanto, ele quer desviar dinheiro, quer ser corrupto. Dever nesse caso é eufórico, ao passo que querer é disfórico. $\mathrm{Na}$ segunda, o volume dos rios sobe, à revelia do desejo dos moradores, mas deve baixar 
para evitar mais morte e destruição. Essa tensão entre o querer e o dever mostra que, na maioria das vezes, este é valorizado euforicamente, ao passo que aquele tem um valor negativo construído pelo texto. Assim, a notícia, ou a noticiabilidade de uma matéria jornalística, nasce de um conflito entre tais modalidades, mais recorrentemente, entre o dever-não-fazer e o querer-fazer.

Dessa maneira, ao enunciatário do telejornal se dirige um fazer-crer e um fazerfazer: o fazer comunicativo. Por jogar luz sobre as quebras de contrato entre os actantes do nível narrativo e, mais concretamente, entre os atores do nível discursivo, o Jornal Nacional reforça um quadro de valores social e moralmente estabelecido, protegendo-o contra possíveis desejos de mudança. Assim, ao empreender um fazer comunicativo que axiologiza euforicamente a modalidade deôntica e disforicamente a volitiva, podemos dizer que o JN atua como Destinador-manipulador que determina os valores do Destinatário-sujeito, figurativizado pelo telespectador.

\section{Relações entre conteúdo e expressão}

O segundo objetivo da pesquisa foi analisar a relação entre o conteúdo e a expressão da fala de forma conjunta. Antes, porém, de adentrarmos a análise, cabe um esclarecimento de natureza teórica. Ao retomarmos as dicotomias hjelmslevianas conteúdo/expressão e substância/forma, tradicionalmente, diz-se que a fonética se ocupa da substância da expressão, enquanto a fonologia se preocuparia com a forma desse funtivo. No entanto, a visão de que a substância cabe à fonética, e forma à fonologia traduz-se numa perspectiva no mínimo discutível, pois ambas as ciências trabalham discretizando o continuum sonoro, cada uma à sua maneira: a fonologia discretiza a representação do som, aquilo que ele tem de estável, ao passo que a fonética discretiza a realização física desse som. Graças a isso, a fonologia pôde se beneficiar de uma forma inteiramente já discretizada pela fonética, como no caso do Alfabeto Internacional de Fonética. Na fonética acústica, a discretização do continuum se observa pela segmentação e, no caso desta pesquisa, tal segmentação se deu pelos segmentos VV (de vogal a vogal). Assim, somente por meio do recorte do continuum, isto é, apenas transformando substância em forma, é possível pensar o modus operandi da fonética, já que sem o corte não há sentido, apenas um magma dessemantizado (HJELMSLEV, 2006), do mesmo modo que, como mostram Greimas e Fontanille (1993), o continuum é precondição necessária à instalação do sentido pelo corte. Além disso, hjelmslevianamente falando, analisar ou agir de forma científica equivale a dividir, e se já se dividiu, já não é mais terreno da substância, mas da forma. Por isso, o presente artigo considera que tanto a fonética quanto a fonologia estudam a forma da expressão da fala. O que as diferencia é que a primeira se guia pela perspectiva da parole, ao passo que a segunda, pela da langue.

À semiótica, por sua vez, cabem as relações entre a forma do conteúdo e a forma da expressão. Destarte, o que propomos nesta pesquisa, de modo algum, foge a uma análise semiótica, pois se correlaciona forma da expressão com forma do conteúdo. 
Para empreender tal análise, foi necessário criar uma interface gráfica ${ }^{2}$ que contivesse os dados fonéticos e os dados semióticos devidamente correlacionados. A interface, ainda em fase alfa, permitiu visualizar todo o texto dividido em grupos acentuais transcritos fonologicamente e, ao lado desses, as caixas de texto para inserção de informações novas, ou seja, aquelas resultadas das análises semióticas. As relações não poderiam ser no nível do segmento fonético mínimo, já que a semiótica trabalha no nível do texto. Optamos, assim, por relacionar as análises semióticas a segmentos do tamanho de um período: os grupos acentuais, doravante, GAs.

Assim, por exemplo, a análise semiótica do andamento do conteúdo do texto constitui uma dessas informações inseridas na interface gráfica. Sob a rubrica de andamento, é possível manualmente determinar se o andamento é acelerado, desacelerado, não acelerado ou não desacelerado. Essa nova informação, inserida com absoluta independência das análises fonéticas que a precederam, constitui um parâmetro para as análises estatísticas, permitindo cruzar os dados de fonética acústica com os dados de semiótica. As outras informações extras são: valor (positivo/negativo) e disposição (do sujeito em questão, dever/querer). Os dados fonéticos com os quais cruzamos dados semióticos foram: duração absoluta do segmento $\mathrm{VV}$, média do primeiro formante ${ }^{3}$ (F1), desvio-padrão de F1, média do segundo formante (F2), desviopadrão de F2, média do terceiro formante (F3), desvio-padrão de $\mathrm{F} 3$, média do quarto formante (F4), desvio-padrão de $\mathrm{F} 4, \mathrm{Z}$ suavizado (variação da duração do segmento em relação à duração esperada conforme seus componentes fonológicos), taxa de elocução (número de segmentos VV por GA), média de F0 (frequência fundamental), desviopadrão de F0, média de pitch do GA, desvio-padrão de pitch de GA. Ressaltamos que os parâmetros fonético-acústicos foram escolhidos para abarcar o maior número possível de variáveis, considerando os limites da coleta de dados naturais, que não possuem controle de intensidade ou controle fonológico.

Os parâmetros semióticos com os quais contrapusemos dados fonéticos pertencem principalmente ao nível discursivo. Cabe notar que disposição e valor, embora sejam dados referentes ao nível narrativo e fundamental, foram obtidos pela análise temático-figurativa do texto; portanto, a partir da análise discursiva. Trata-se, assim, de elementos cuja existência se dá no texto de forma concreta, diferentemente dos níveis narrativo ou fundamental. Matte (2008) realizou uma investigação cujo intuito foi cruzar dados fonéticos e semióticos, estes relativos ao nível narrativo, principalmente no que concerne ao caráter emotivo de ambos os planos da função semiótica. A autora afirma:

Tendo trabalhado durante anos com base nesse arcabouço [semiótico], decidimos, no presente trabalho, fazer uma pesquisa às avessas: se a teoria nos diz que a narrativa tem pouco ou nada a ver com o problema [a questão da fala], vamos testar interdisciplinarmente justamente elementos do nível narrativo para

\footnotetext{
2 A criação dessa interface foi prevista no projeto original do SetFon: algoritmo para produção $e$ organização de semioetiquetas fonológicas, coordenado pela $\operatorname{Prof}^{a} \operatorname{Dr}^{a}$. Ana Cristina Fricke Matte.

3 A onda periódica simples tem uma única freqüência, de modo que toda sua energia está concentrada num dado nível de energia. Ao contrário, as ondas complexas, formadas por duas ondas simples, terão dois picos em que a energia se concentra; esses picos de energia são chamados de formantes. O espectro da onda mostra o ponto em que há essa concentração de energia.
} 
verificar se, em algum ponto, essa premissa cai por terra ou, pelo menos, deveria ser revista (MATTE, 2008, p. 2).

Matte (2008) parte da premissa de que o nível narrativo não está vinculado à emoção, já que se trata de uma estrutura lógica e não cronológica, enquanto a emoção é aspectual, principalmente no que se refere à intensidade e à temporalidade. Após o cruzamento de dados fonéticos e semióticos, a autora conclui que as premissas a respeito da narrativa se verificam na pesquisa, isto é, as análises mostraram uma desvinculação entre plano de conteúdo e plano de expressão, assim como previa a hipótese da autora. Tal desvinculação se dá pelo fato de o nível narrativo ser um nível lógico e abstrato, cujas relações não correspondem diretamente ao plano da expressão.

Ao se trabalhar com o nível discursivo, ou seja, o nível mais concreto do plano do conteúdo, vislumbramos a possibilidade de serem descobertos resultados diferentes daqueles encontrados por Matte (2008), uma vez que se trata de outro nível do percurso gerativo de sentido. Desse modo, Barros (2007, p. 53) afirma:

O nível discursivo é o patamar mais superficial do percurso, o mais próximo da manifestação textual. Pela própria definição do percurso gerativo, estruturas discursivas são mais específicas, mas também mais complexas e "enriquecidas" semanticamente que as estruturas narrativas e fundamentais.

Segundo a autora, o sujeito da enunciação faz escolhas relacionadas à pessoa, ao espaço e ao tempo, bem como a temas e figuras; essa escolha engendraria a passagem da narrativa para o discurso. Portanto, esse nível se caracteriza por ser o mais complexo, mais marcado por escolhas do sujeito da enunciação e, além disso, o mais próximo da manifestação textual. Assim, justifica-se uma análise que pretenda perceber como se relacionam as estruturas discursivas com a manifestação do texto, isto é, com dados fonéticos. Por fim, salientamos que os dados acústicos foram obtidos com completa independência dos dados semióticos, o que confere força aos resultados encontrados.

\subsection{Análise das relações entre conteúdo e expressão}

$\mathrm{Na}$ esteira de Matte (2008), cruzamos dados semióticos provenientes de análise temático-figurativa e aspectual do texto; portanto, a partir do nível discursivo. Os resultados desta pesquisa apontam para o que vislumbrou a autora, ou seja, que, ao se trabalhar com o nível discursivo, dados fonéticos são afetados por dados semióticos. Em outras palavras, o conteúdo atua modificando a expressão.

Isso pode ser comprovado, no caso da etiqueta semiótica valor (positivo/negativo), isto é, quando o texto valora eufórica ou disforicamente tal tema ou figura. A maioria dos GAs etiquetados com "negativo" apresentaram a maior média de 
frequência e o maior desvio-padrão de F1, F2, F3 e F4 4 . Salienta-se que o F4, segundo a literatura, é o formante que é mais afetado pela emoção e, portanto, pelo conteúdo (MATTE, 2002). No entanto, resultados da pesquisa indicam que os demais formantes também se alteram pelo conteúdo. Por exemplo, no caso de F1 e valor, foi feita uma análise de variância ANOVA one-way e foram obtidos os seguintes resultados: $\mathrm{DF}=4$, SumSq $=1807541$, Mean $=451885, F=9.505, p<0,001$. O resultado estatístico, de diferença altamente significativa, mostrou que os GAs etiquetados com o valor negativo são os que possuem maior média de F1, o que significa que o valor "negativo" afeta o primeiro formante, como se observa no gráfico a seguir:

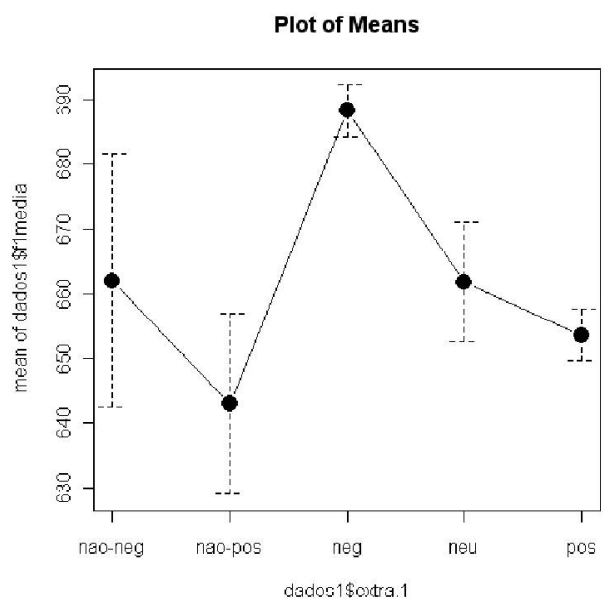

Valor semiótico no eixo x e média de F1 no eixo y

Observamos também que a taxa de elocução é mais lenta em "não positivo", que, segundo o quadrado semiótico, tende ao negativo. Eis o resultado estatístico obtido por meio de análise de variância ANOVA one-way: $\mathrm{DF}=4, \mathrm{SumSq}=15.4$, Mean $=3.9$, $\mathrm{F}=3.4061, \mathrm{p}<0,01$. No gráfico, podemos perceber tal resultado, que indicaria um efeito de preparação para a atuação do valor negativo pelos formantes:

\footnotetext{
${ }^{4}$ Os demais resultados acerca de valor e formantes encontrados por análise de variância ANOVA oneway, que apresentaram diferenças altamente significativas, são: para desvio-padrão de F: $\mathrm{DF}=4$, SumSq $=3205445$, Mean $=801361, \mathrm{~F}=21.239, \mathrm{p}<0,001$; para média de F2: DF=4, SumSq = 12899816, Mean $=$ 3224954, F = 25.003, p < 0,001; para desvio-padrão de F2: DF=4, SumSq = 704417, Mean $=176104, \mathrm{~F}$ $=3.7085, \mathrm{p}<0,01$; para média de F3: $\mathrm{DF}=4$, SumSq $=4905641$, Mean=1226410, F = 14.134, $\mathrm{p}<0,001$; para desvio-padrão de F3: $\mathrm{DF}=4, \mathrm{SumSq}=1509797$, Mean $=377449, \mathrm{~F}=10.952, \mathrm{p}<0,001$; para média de F4: DF=4, SumSq = 2196310, Mean=549077, F=7.0201, $\mathrm{p}<0,001$.
} 


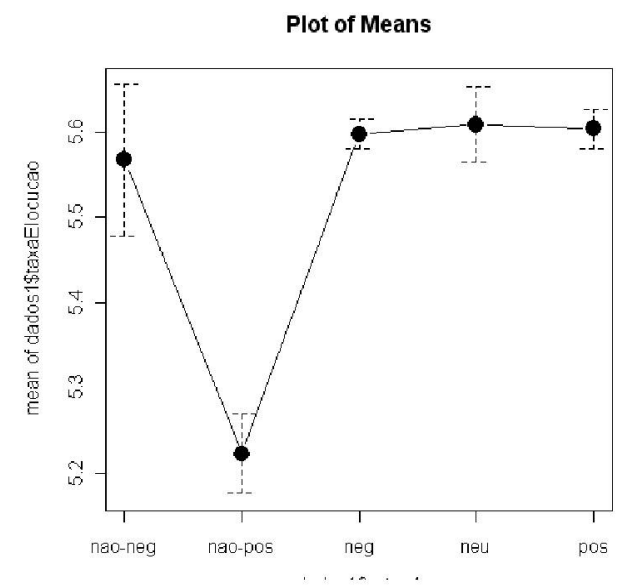

Valor semiótico no eixo x e taxa de elocução no eixo y

Após o cruzamento da etiqueta semiótica valor com os dados fonéticos, observamos um padrão: o valor negativo do plano do conteúdo sempre tornou os quatro primeiros formantes - do plano da expressão - mais altos. Isso significa que, nos trechos do texto valorados negativamente, a qualidade vocálica se modifica, produzindo um efeito de sonoridade mais aguda. Poder-se-ia pensar que esse agudo seria fruto da coincidência de uma repórter do sexo feminino ao narrar matérias disforicamente marcadas. Argumentamos, no entanto, que seria impossível que as mulheres se concentrassem apenas em textos negativos, pois houve mudanças de valor até mesmo dentro da mesma frase. Corrobora essa assertiva o comportamento do gráfico de F0 para valor, que mostrou não haver correspondência entre o valor de F0 e formantes. Isso descartaria a hipótese de uma possível correspondência entre vozes femininas narrando notícias de valor negativo, já que vozes femininas apresentam média de F0 maior que vozes masculinas.

A etiqueta disposição (querer/dever) também mostrou atuar sobre padrões fonéticos. GAs etiquetados com "querer" apresentaram F2, F3 ${ }^{5}$ e F4 com maior média de frequência, com relação aos GAs marcados pela etiqueta "dever". Como exemplo, apresentamos o gráfico da média do quarto formante em relação às etiquetas "dever/querer", criado da ANOVA one-way, que apresentou os seguintes resultados com diferença altamente significativa: $\mathrm{DF}=1, \mathrm{SumSq}=405521$, Mean $=405521, \mathrm{~F}=$ $5.1687, \mathrm{p}<0,1$. Como vemos no gráfico, os GAs marcados pelo querer têm uma média de F4 maior que aqueles marcados pelo dever.

\footnotetext{
5 A análise de variância ANOVA one-way para média de F2 e valor (querer/dever) (DF = 1, SumSq = 1991127, Mean $=1991127, \mathrm{~F}=15.245, \mathrm{p}<0,001)$ encontrou diferença altamente significativa, que mostra que o F2 de querer varia mais que o F2 de dever. O mesmo se observou com média de F3 (DF $=1$, SumSq $=2337077$, Mean $=2337077, \mathrm{~F}=26.823, \mathrm{p}<0,001)$.
} 


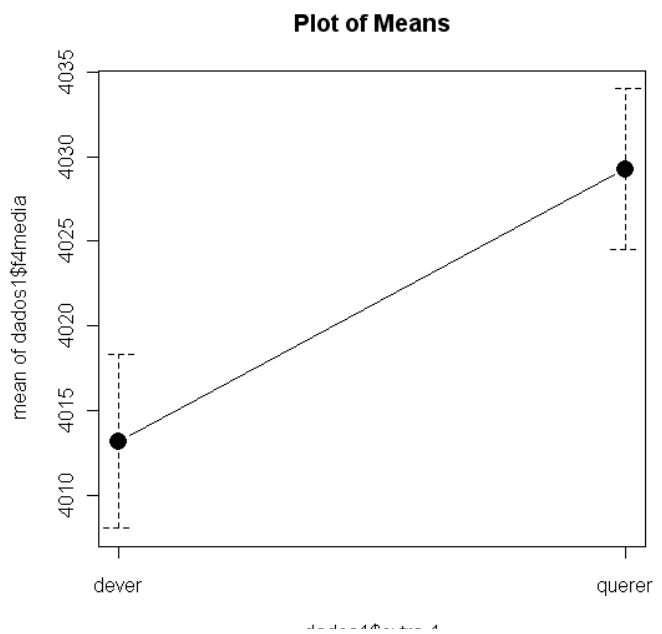

Gráfico com médias com disposição semiótica no eixo x e média de F4 no eixo y

Quanto ao desvio-padrão, os quatro primeiros formantes mostraram maior variabilidade quando etiquetados com "querer" ${ }^{6}$. Dessa forma, assim como na etiqueta valor, em disposição, percebemos que é nos formantes que ocorre uma relação em que o conteúdo afeta a expressão. As etiquetas "querer" e "negativo", ao apresentarem resultados coincidentes, confirmam estatisticamente uma maior disforização do querer e euforização do dever, mostrada pelas análises semióticas. Disso se depreende que, pelos dados analisados, tanto fonética como semioticamente, o JN atua como Destinadormanipulador que axiologiza positivamente o dever e negativamente o querer.

O último dado semiótico que comparamos com dados acústicos foi o andamento nos textos, isto é, se o andamento é acelerado, significa maior intensidade e, por isso, presença de ruptura, por meio da apresentação de temas e figuras. Se, por outro lado, o texto tem um andamento desacelerado, essa extensidade é fruto de um texto mais descritivo e/ou explicativo. Assim, a etiqueta andamento também mostrou influenciar dados fonéticos. Os grupos acentuais marcados com "desacelerado" mostraram média maior que os GAs marcados com "acelerado" nos quatro primeiros formantes ${ }^{7}$.

\footnotetext{
${ }^{6}$ Aplicou-se análise de variância ANOVA one-way e encontrou-se diferença altamente significativa quanto ao desvio padrão dos quatro primeiros formantes, que mostraram que os segmentos marcados pelo querer possuem maior variação de F1, F2, F3 e F4 do que aqueles marcados pelo dever. A seguir apresentam-se os valores encontrados: $\mathrm{F} 1: \mathrm{DF}=1, \mathrm{SumSq}=963568$, Mean $=963568, \mathrm{~F}=963568, \mathrm{p}<$ 0,001; F2: DF $=1$, SumSq $=814580$, Mean $=814580, F=17.168, p<0,001 ; F 3:$ DF $=1$, SumSq $=$ 361052 , Mean $=361052, \mathrm{~F}=10.427, \mathrm{p}<0,01 ; \mathrm{F} 4: \mathrm{DF}=1, \mathrm{SumSq}=242175$, Mean $=242175, \mathrm{~F}=8.4034$, $\mathrm{p}<0,01$.

${ }^{7}$ A seguir apresentam-se os resultados estatísticos dos encontrados por meio de análise de variância ANOVA one-way entre formante e andamento (acelerado/desacelerado), todos apresentando diferença altamente significativa: $\mathrm{F} 1: \mathrm{DF}=3, \mathrm{SumSq}=1793630$, Mean $=597877, \mathrm{~F}=12.577, \mathrm{p}<0,001 ; \mathrm{F} 2: \mathrm{DF}=$ 3 , SumSq $=9368359$, Mean $=3122786, F=24.113, \mathrm{p}<0,001 ; \mathrm{F} 3: \mathrm{DF}=3$, SumSq $=11778819$, Mean $=$ 3926273, F $=45.818, \mathrm{p}<0,001 ; \mathrm{F} 4: \mathrm{DF}=3, \mathrm{SumSq}=20513910$, Mean $=6837970, \mathrm{~F}=90.734, \mathrm{p}<$ 0,001 .
} 
Além disso, os GAs marcados com "acelerado" possuem taxa de elocução maior que o desacelerado, cuja TE é próxima ao não acelerado, ou seja, os grupos acentuais com conteúdo mais acelerado influem na expressão, que apresenta uma taxa de elocução maior, isto é, mais segmentos VV por GA. A análise do índice de variância ANOVA one-way foi altamente significativa $(\mathrm{DF}=3, \mathrm{SumSq}=51.9$, Mean $=17.3, \mathrm{~F}=$ $15.369, \mathrm{p}<0,001)$. O gráfico que ilustra esse resultado é apresentado a seguir:

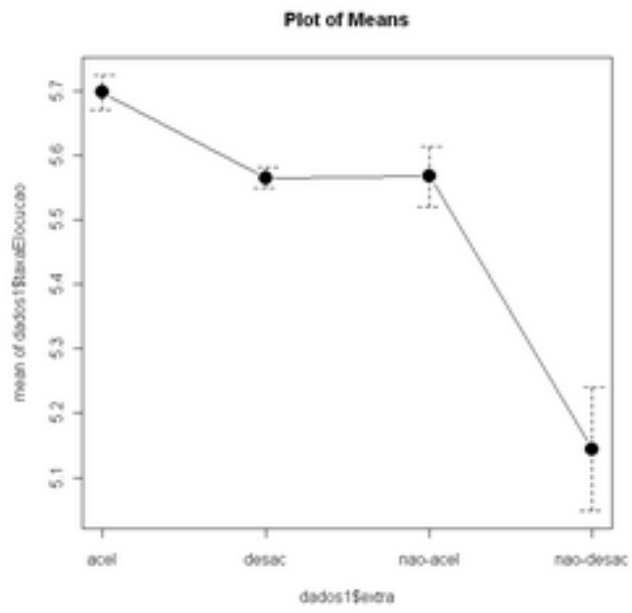

Gráfico com médias com andamento semiótico no eixo x e taxa de elocução no eixo y

Esse resultado indicaria mais uma relação entre conteúdo de andamento acelerado, ou seja, um texto de muitas rupturas, no plano do conteúdo, e, portanto, de maior intensidade e, no plano da expressão, uma taxa de elocução alta, ou seja, abertura e fechamento mais rápidos da mandíbula para a produção do sinal de fala, remetendo às leis saussurianas da silabação, cujos fundamentos foram desdobrados também para o plano do conteúdo pela semiótica ${ }^{8}$. Esses resultados se mostram em consonância com a teoria semiótica, que amplia a ideia de silabação para o plano do conteúdo, que, assim como a expressão, regula-se por continuidades e descontinuidades.

\footnotetext{
${ }^{8}$ Em relação à sílaba, a semiótica propõe uma interessante relação entre conteúdo e expressão. Para Tatit (1997), durante muito tempo, essa disciplina, ao tomar o discurso (conteúdo) como objeto de análise, retirou de seu escopo a expressão, de modo que se passou por cima das proposições saussuriana (significante/significado) e hjelmsleviana (função semiótica). O resgate, por assim dizer, do plano da expressão, tem a ver com as leis rítmicas de silabação: "A importância da sílaba como categoria abstrata foi introduzida por Saussure, definida e estendida ao plano de conteúdo por Hjelmslev e generalizada por Zilberberg na qualidade de categoria universal para a aplicação de todos os domínios semióticos" (TATIT, 1997:19). A afirmação de Tatit se refere àquilo que se chama de prosodização da semiótica. Para o autor, a silabação mostra de que maneira o ritmo influencia o tempo cronológico. Dessa forma, em se tratando da silabação, a abertura sonora aponta para o seu fechamento e vice-versa. Para Saussure, uma soante será sempre delimitada por uma consoante assim como o contrário. Tal ritmo dará origem aos conceitos saussurianos de fronteira silábica (demarcações e limites) e ponto vocálico (segmentações e extensões).
} 


\section{Conclusão}

Ao empreendermos uma investigação interdisciplinar para o estudo do conteúdo e da expressão, analisamos a fala em processo e encontramos relações que a cultura reconhece e que não foram descritas antes. Tais conclusões a que chegamos neste artigo, por meio do cruzamento estatístico de dados fonéticos e semióticos, poderiam sugerir que, em condições habituais, não se poderia supor a existência de relações simbólicas entre conteúdo e expressão, tais como foram atestadas aqui. Sabemos, no entanto, que se faz uso, mas não se tem consciência do sistema. Como apontou Hjelmslev (2006 p. 3), "[...] é destino natural [da fala humana] ser um meio e não um fim". Eis a função da ciência: desvelar processos com os quais se convive, mas que não se sabe explicar.

Finalmente, cabe ratificar que cada frente de pesquisa da qual deriva o presente artigo contou com pressupostos teórico-metodológicos diferentes que, no entanto, mostraram ser perfeitamente articuláveis. $\mathrm{O}$ ineditismo dos resultados aqui expostos confirma a proficuidade do recente campo de estudos, a semiofonoestilística, que envolve o trabalho interdisciplinar da semiótica do discurso e da fonética acústica para o estudo do conteúdo e da expressão da fala, cujos precedentes foram abertos por Matte $(2002,2008)$.

\section{Referências bibliográficas}

ALBANO, E. C.; MOREIRA, A. A. Archisegment-based letter-to-phone conversion for concatenative speech synthesis in Portuguese. In: ICSLP-1996, 1708-1711, 1996.

BARBOSA, P. A. Incursões em torno ao ritmo de fala. Campinas: Pontes Editores, São Paulo: FAPESP, 2003.

BARROS, D. L. P. de. Teoria semiótica do texto. 4. ed. São Paulo: Ática, 2007.

BARROS, D. L. P. de. Teoria do discurso: fundamentos semióticos. 3. ed. São Paulo: Humanitas: USP, 2002.

FIORIN, J. L. Elementos de análise do discurso. 14. ed. São Paulo: Contexto, 2006.

FIORIN, J. L. Sendas e Veredas da Semiótica Narrativa e Discursiva. DELTA, São Paulo, v. 15, n. 1, 1999.

GREIMAS, A. J.; COURTÉS, J. Dicionário de Semiótica. São Paulo: Contexto, 2008. 
GREIMAS, A. J.; FONTANILLE, J. Semiótica das paixões: dos estados de coisa ais estados de alma. São Paulo: Ática, 1993.

HJELMSLEV, L. Prolegômenos a uma teoria da linguagem. São Paulo: Perspectiva, 2006.

MATTE, A. C. F. Vozes e canções infantis brasileiras: emoções no tempo. Tese (Doutorado em Semiótica e Linguística Geral) - Universidade de São Paulo, 2002

Emoção e narrativa: conteúdo e expressão na fala. In: III Simpósio Internacional sobre Análise do Discurso, 2008, Belo Horionte. III Simpósio Internacional sobre Análise do Discurso: resumos. Belo Horizonte : NAD - Núcleo de Análise do Discurso/UFMG, 2008.

MENDES, C. M., MATTE, A. C. F. Relations between content and expression of Jornal Nacional's parole: a semiophonostylistic approach.

MENDES, C. M. A expressão e o conteúdo da fala do Jornal Nacional. Dissertação (Mestrado em Estudos Linguísticos) - Universidade Federal de Minas Gerais, 2009.

ORGANIZAÇÕES GLOBO. Jornal Nacional: a notícia faz história/Memória Globo. Rio de Janeiro: Jorge Zahar, 2004.

SAUSSURE, F. de. Curso de lingüistica geral. 27. ed. São Paulo : Cultrix, 2006.

TATIT, L. Musicando a semiótica: ensaios. São Paulo: Annablume, 1997.

\begin{abstract}
This article is the result of a study, the objectives of which were: (1) examine how meaning is constructed on Jornal Nacional, the most important Brazilian TV newscast; (2) determine how the content and expression relate. In order to work on the two levels of the two levels of language implementation, it was necessary, on the one hand, to resort to the Acoustic Phonetics, discipline which examines the physical characteristics of speech sounds, and, on the other hand, to the theoretical and methodological scope of the French Semiotics, discipline that is interested in intra-textual mechanisms of production of meaning in the text. As to the first goal, as the semiotic analysis of the news on Jornal Nacional was carried out, it was observed that some structures, on which the discourse of the TV newscast is built, are invariant. The texts were analyzed primarily as far as the discursive level is regarded, foreseen by the process of meaning generation. As to the second goal, as proposed by Matte (2008), phonetic and semiotic data extracted from the discursive level were compared. Unpublished results point to a framework in which some elements of the content plan affect, in the Jornal Nacional parole, elements of the expression plan in statistically significant analysis.
\end{abstract}

Keywords: French Semiotics; content plan; Acoustic Phonetics; expression plan; TV news; semiophonostylistics.

ANEXO: 


\section{Texto integral da primeira matéria analisada}

A Justiça de São Paulo mandou para o Supremo Tribunal Federal o processo em que o nome do deputado federal Paulo Pereira da Silva, do PDT, aparece citado como beneficiário de um esquema de desvio de dinheiro do Banco Nacional de Desenvolvimento Econômico e Social. O deputado Paulo Pereira da Silva, o Paulinho da Força Sindical, não apareceu no gabinete da Câmara. Ficou em São Paulo preparando as explicações que vai dar amanhã ao PDT, partido dele. Para o Ministério Público, há indícios da participação do deputado no esquema. Em entrevista, a procuradora que cuida do caso disse que os indícios vão além das escutas telefônicas. "O indício que seja ele são as ramificações das investigações e, na verdade, algumas vezes não foi só citado o nome Paulinho". A procuradora disse que, nas escutas telefônicas, há evidências da participação de 11 prefeituras. Também foram encontrados indícios do envolvimento de funcionários do BNDES. Foram feitos 11 pedidos de prisão. Prefeitos e deputados têm foro privilegiado. Por isso, o Ministério Público pediu e a Justiça Federal de São Paulo enviou cópias do processo ao Tribunal Regional Federal e ao Supremo Tribunal Federal. Para processar o deputado Paulo Pereira da Silva, o STF depende do parecer da Procuradoria Geral da República, que pode pedir ou não a abertura de inquérito contra o deputado. "A hora que chegar eu vou examinar para verificar. Se tiver alguma coisa, eu tomo as providências que eu sempre tenho tomado". Em nota, a Força Sindical defendeu seu presidente, dizendo que ele é vítima de implacável perseguição política.

\section{Texto integral da segunda matéria analisada}

A Defesa Civil em Porto Alegre confirmou hoje a segunda morte causada pelo ciclone extratropical que atingiu a Região Sul do Brasil no fim de semana. Depois da chuva, a preocupação agora é com os rios que não param de subir. Em Taquara, a 70 quilômetros de Porto Alegre, o Rio dos Sinos está oito metros acima do nível normal. Centenas de casas ficaram submersas. "Chegou de repente, pegou todo mundo desprevenido".De barco, os moradores ainda tentam salvar alguns móveis. "Perdi roupa, perdi móvel, dentro de casa, TV, rádio, tudo eu perdi, tudo ali dentro". No fim de semana, a chuva e os ventos de mais de $100 \mathrm{~km} / \mathrm{h}$ arrancaram árvores, destruíram casas e a rede elétrica de muitas cidades. Nove mil e quinhentos consumidores ainda estão sem luz. Em protesto, moradores de Guaíba, na Grande Porto Alegre, fecharam hoje uma das principais avenidas da cidade. "Nós resolvemos protestar porque desde sexta-feira, às oito e meia, nós estamos sem luz. Estragou toda a nossa alimentação". Nesta rua da capital gaúcha, a calçada cedeu bem debaixo de um veículo que estacionava. A motorista do carro e o filho dela, de cinco anos, tiveram que sair pelo porta-malas. "Tentaram quebrar o vidro. Eu acho que ela mesma conseguiu acionar o porta-malas e abriu. Os vizinhos tentaram tirar ela pelo porta-malas. Graças a Deus que não se machucaram, né”. Por causa da passagem do ciclone, sete cidades decretaram situação de emergência. Três mil pessoas ainda não voltaram para casa. O temporal fez duas vítimas no Rio Grande do Sul. Na noite de ontem, um homem morreu afogado na serra gaúcha. Em Santa Catarina, na divisa com o Rio Grande do Sul, a BR 101 está interditada desde o fim da tarde de ontem. A rodovia foi inundada depois que um rio da região transbordou. $\mathrm{O}$ engarrafamento já chega a 14 quilômetros. Os temporais dos últimos dias atingiram 32 
municípios do estado. A situação é mais grave no sul. Em Ermo, esta casa foi arrastada para dentro do rio. Muitas comunidades rurais ainda estão isoladas. Hoje, quando a água começou a baixar, dona Aurora voltou para casa e se desesperou ao ver a destruição causada pela enchente. "Perdi o que tinha de roupa, e comida, e coisa. Não dá para aproveitar mais nada". A falta de água dificulta a limpeza da lama. Todos os pertences de dona Maria Bento ficaram espalhados pelo terreno. "Nós tá com essa muda de roupa aqui. Nós tiramos uma muda de roupa de cada um e uma caixinha de leite. O resto ficou ali". Na passagem do ciclone, entre a sexta-feira e o domingo, choveu três vezes mais do que o esperado para o mês inteiro em algumas cidades do Sul. A água que desceu das montanhas transformou ruas em rios. Oito municípios já decretaram situação de emergência. A preocupação da Defesa Civil é com o frio. Pelo menos mil e seiscentas pessoas estão desalojadas. "A maior preocupação é fazer chegar alimento e agasalhos para a população que está desabrigada, desalojada e alguns isolados, porque a previsão, neste momento, é frio". 